\title{
Characterization of Electrostatic Discharge Properties of Woven Fabrics
}

\section{Perumalraj $\mathbf{R}^{*}$}

Bannari Amman Institute of Technology, Sathyamangalam, Erode, India

\begin{abstract}
In this research work, the woven fabric samples of cotton, polyester PC blend, glass and silk materials have been selected to analyze the electrostatic discharge behavior of various woven fabrics using electrostatic discharge tester. The electrostatic discharge is mainly depends upon various controlled factors of electrostatic discharge tester hence, the controlled factors of number of rubbing cycle (20,30 and 40 strokes), pressure (100,150 and 200 gms), speed $(10,20$ and $30 \mathrm{mpm})$ were considered and analyzed the electrostatic discharge behaviors of various woven fabrics under various temperature and relative humidity using Box Behnken design and regression analysis. It was found that the glass and silk woven fabric have greatest tendency to give up electrons and gain a positive electrical charge but in case of polyester woven fabric have the greatest tendency to attract electrons and gain a negative electrical charge. It was observed that glass woven fabrics have more electrostatic discharge value than the polyester, PC blend, silk and cotton woven fabrics and it was also found that higher number of rubbing cycle, pressure and speed have significant effects on the electrostatic discharge properties of various types of woven fabrics.
\end{abstract}

Keywords: Electrostatic discharge; Box-Behnken method; Tribo electric effect; Static electricity; Regression analysis

\section{Introduction}

Electrostatic discharge (ESD) is the release of static electricity when two objects come into contact. Materials are made of atoms that are normally electrically neutral because they contain equal numbers of positive charges (protons in their nuclei) and negative charges (electrons in "shells" surrounding the nucleus). The phenomenon of static electricity requires a separation of positive and negative charges. When two materials are in contact, electrons may move from one material to the other, which leaves an excess of positive charge on one material, and an equal negative charge on the other. When the materials are separated they retain this charge imbalance [1-4]. During textile manufacturing process, there is a potential of static charge generation when fibers are extruded, and yarns are woven or knitted, and finished. Fibers, yarns, or fabrics are rubbed with guides, rollers or tension devices on the machinery and this operation of contact and separation continuously occur throughout the process [5-8]. This gives many spinners and weavers much trouble in terms of productivity, and can lead to malfunction of electronic equipment [9-12]. Static problems in textile industry have become more serious problems in synthetic fibre production [13-19]. There are many factors that affect charge generation such as environment (temperature, humidity), structural (polymer type, structure of fabric) and working factors (fabric speed, tension, and contact area between fabric and machine parts, material type that is in contact with fabric $[20,21]$. From the literature survey, there is no extensive study about the electrostatic discharge properties of various types of woven fabric. Hence In this research work, the woven fabric samples of cotton, polyester PC blend, glass and silk materials have been selected to analyze the electrostatic discharge behavior of various woven fabric using electrostatic discharge tester. The electrostatic discharge is mainly depends upon various controlled factors of electrostatic discharge tester hence, the controlled factors of number of rubbing cycle (20, 30 and 40 strokes), pressure (100,150 and $200 \mathrm{gms})$, speed $(10,20$ and $30 \mathrm{mpm})$ were considered and analyzed the electrostatic discharge behaviors of various woven fabrics under various temperature and relative humidity using Box Behnken design and regression analysis.

\section{Materials and Methods}

The woven fabric samples of cotton, polyester, polyester/cotton blend, silk and glass with a sample size of 10 inch $\times 5$ inch were selected to analyze the electrostatic charge behavior of woven fabric using electrostatic discharge tester. All the selected woven fabrics were made with plain weave and same ends per inch (30), picks per inch (30). The electrostatic charge properties are mainly depends upon various controlled factors and uncontrolled factors namely number of rubbing cycle, pressure, speed, temperature and relative humidity (RH). In order to analyze and optimize the process parameters of electrostatic discharge tester, the following three factors were considered to analyze the electrostatic discharge properties of textile materials i.e., number of cycles (X1), pressure(X2) and speed (X3) by using Box-Behnken design as shown in the Table 1 . The varying values of rubbing cycle(X1) are 20,30 and 40 strokes; the varying values of pressure(X2) are 100,150 and $200 \mathrm{gms}$. The varying values of speed (X3) are 10, 20 and $30 \mathrm{mpm}$ under temperature $\left(27^{\circ} \mathrm{C}\right)$ and $\mathrm{RH}(50 \%)$ as shown in the Table 1 . In electrostatic discharge tester, the sample is fixed between clamp1 and 2 . The required parameters are fed into the electrometer before hand and the arm consisting the weight at the top and Teflon roller at the bottom is moved over the fabric in a linear reciprocating to and fro manner over the fabric. Finally the linear reciprocating movement is stopped after the predetermined values are reached, where the rubbing strokes is sensor by the proximity sensor and the static charge produced on the fabric can be measured by the electrostatic sensor. As per the coulombs law the force, pressure, speed were directly proportional to the amount of charge produced. The range of static charge that can be measured in the range of 1-15 kilovolts. When Teflon roller is moved over the fabric, the electrostatic charge is generated on the fabric, and then static charge can be sensed by electro static sensors. The electrostatic discharge values of various woven fabrics were analyzed using Box

*Corresponding author: Rathinam Perumalraj, Bannari Amman Institute of Technology, Sathyamangalam, Erode, India, Tel: 91-422-2302277; E-mail: raj134722002@gmail.com

Received November 14, 2015; Accepted January 09, 2016; Published January 19, 2016

Citation: Perumalraj R (2016) Characterization of Electrostatic Discharge Properties of Woven Fabrics. J Textile Sci Eng 6: 235. doi:10.4172/21658064.1000235

Copyright: ( 2016 Perumalraj R. This is an open-access article distributed under the terms of the Creative Commons Attribution License, which permits unrestricted use, distribution, and reproduction in any medium, provided the original author and source are credited. 
Citation: Perumalraj R (2016) Characterization of Electrostatic Discharge Properties of Woven Fabrics. J Textile Sci Eng 6: 235. doi:10.4172/21658064.1000235

Page 2 of 6

\begin{tabular}{|l|c|c|c|}
\hline \multicolumn{5}{|c|}{ Factor level combination } \\
\hline Expt Run & $\mathbf{X 1}$ & $\mathbf{X 2}$ & $\mathbf{X 3}$ \\
\hline & 20 & 100 & 20 \\
\hline & 40 & 100 & 20 \\
\hline & 20 & 200 & 20 \\
\hline & 40 & 200 & 20 \\
\hline & 20 & 150 & 10 \\
\hline & 40 & 150 & 10 \\
\hline & 20 & 150 & 30 \\
\hline & 30 & 150 & 30 \\
\hline & 30 & 100 & 10 \\
\hline & 30 & 200 & 10 \\
\hline & 30 & 100 & 30 \\
\hline & 30 & 200 & 30 \\
\hline & 30 & 150 & 20 \\
\hline
\end{tabular}

Table 1: Box-Behnken method.

Behnken design and regression analysis.

\section{Results and Discussion}

The static electricity of woven fabrics is mainly depends upon the various factors like speed, pressure and number of rubbing cycles, temperature and RH. In general, when the temperature is high, the static charge generation will be more but when humidity is high, the static charge generation will be less. The various type of woven fabrics have a tendency of either giving up electrons and become positive $(+)$ in charge (or) attracting electron and become negative $(-)$ in charge when brought in contact with other materials. The glass and silk woven fabric materials have tend to give up electrons and gain a positive electrical charge when brought in contact with other materials but the polyester woven fabrics have tend to attract electrons and gain a negative electrical charges when brought in contact with other materials. In case of cotton woven fabric do not tend to get to attract or giving up electrons when brought in contact or rube with other materials. The tribo electric effect (tribo electric charging) is a type of contact electrification in which sudden materials become electrically charged after the come in to contact with other materials through friction. Any two materials are come into contact and then separate, the electron to be exchange. After coming in contact, the chemical bond is formed between parts of the two surfaces, called adhesion, and electrical charges move from one material to other material in order to equalize the electrochemical potential.

\section{Electrostatic discharge properties of polyester woven fabrics}

It was observed from the Figures 1-3, that the polyester woven fabric have more static charge generation range from 1.11 to 2.60 kilovolts under various controlled factors of rubbing cycles, pressure and speed as per the Box Behnken experimental design. The polyester woven fabrics have more static discharge value than cotton and silk woven fabrics. It is mainly due to the moisture regain value of polyester woven fabrics $(0.4 \% \mathrm{MR})$. The polyester woven fabric have less moisture absorption properties and retain more static charge than the natural fibres and also the polyester material are hydrophobic in nature which hardly allows moisture through polyester woven fabric material. Hence polyester woven fabric does not able to dissipate or conduct the electrostatic charges. It was also observed that there is no significant difference of electrostatic charge of polyester woven fabrics

under high and low humidity conditions. It was understood that there was a significant effect between number of rubbing cycle and pressure

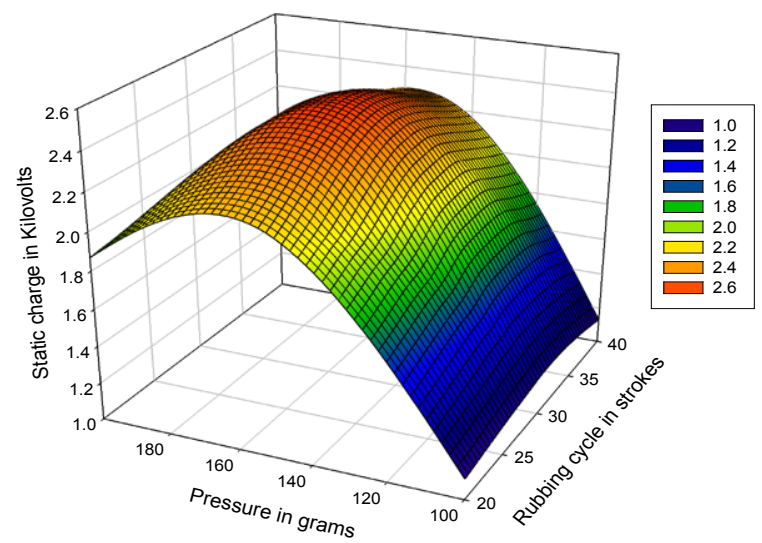

Figure 1: Effect of pressure and rubbing cycle on electrostatic discharge properties of polyester fabrics.

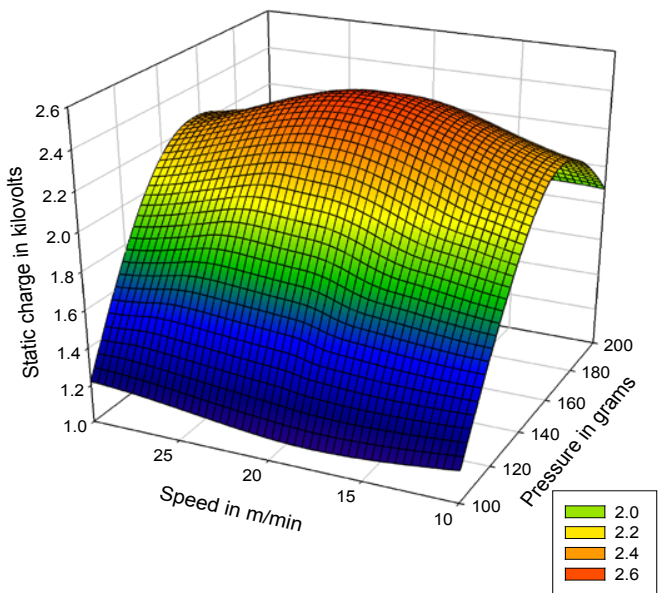

Figure 2: Effect of pressure and speed on electrostatic discharge properties of polyester fabrics.

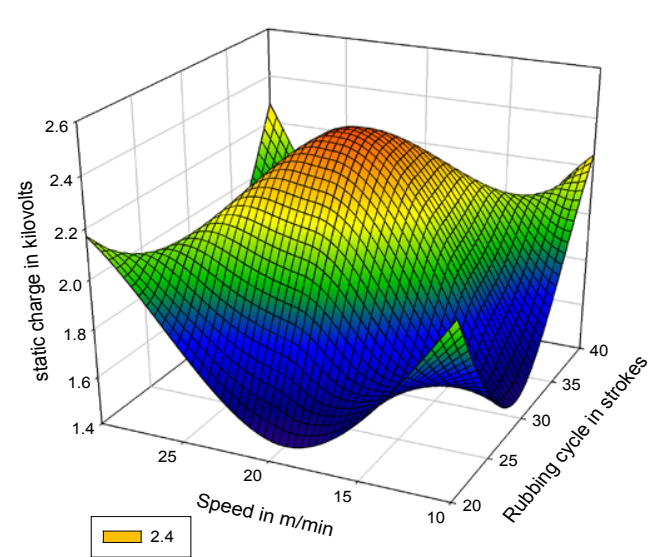

Figure 3: Effect of rubbing cycle and speed on electrostatic discharge properties of polyester fabrics. 
and speed on electrostatic discharge properties of polyester woven fabrics. It was also found that higher number of rubbing cycle, pressure and speed had significant influences on the electrostatic discharge properties.

\section{Electrostatic discharge properties of cotton woven fabrics}

It was observed from Figures 4-6, that the cotton woven fabric have less electrostatic discharge value range from 1.11-1.53 kilovolts under the various controlled factors of number of rubbing cycle, speed and pressure as per the Box Behnken experimental design. The cotton woven fabrics have less electrostatic discharge than Polyester, PC blends, silk and glass woven fabrics. It is mainly due to moisture regain value of cotton materials. The cotton woven fabric moisture regain value is $8 \%$ but the polyester woven fabric moisture regain value is only $0.4 \%$. The cotton fibers have $70 \%$ of crystalline region and rest of region is amorphous and cotton fibre is very absorbent owing to the counter less polar $\mathrm{O}-\mathrm{H}$ group in its polymer, these attract water molecules. Hence this water conducts and dissipates the static electrical charge. There is a significant difference between cotton, PC blends and glass woven fabrics of electrostatic discharge properties. This cotton fabric moisture will able to contain and helps to distribute/dissipate the electrostatic charge very easily. However the observed moisture particle is actually conducting the electrical static charge and not the cotton fibre itself. It

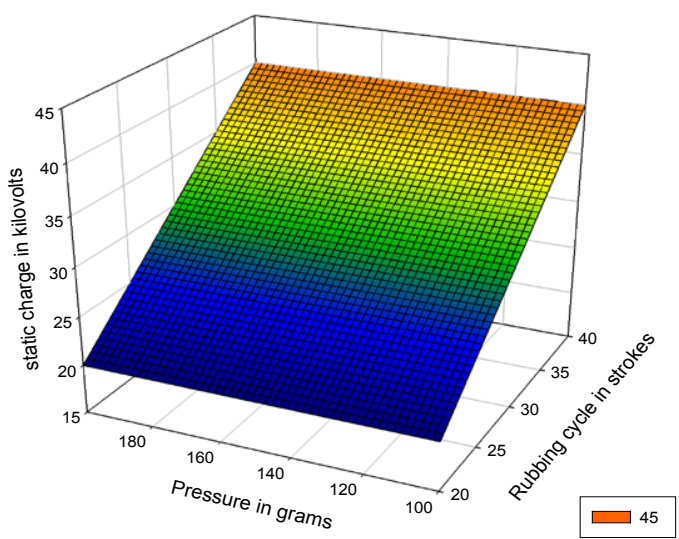

Figure 4: Effect of pressure and rubbing cycle on electrostatic discharge properties of cotton fabrics.

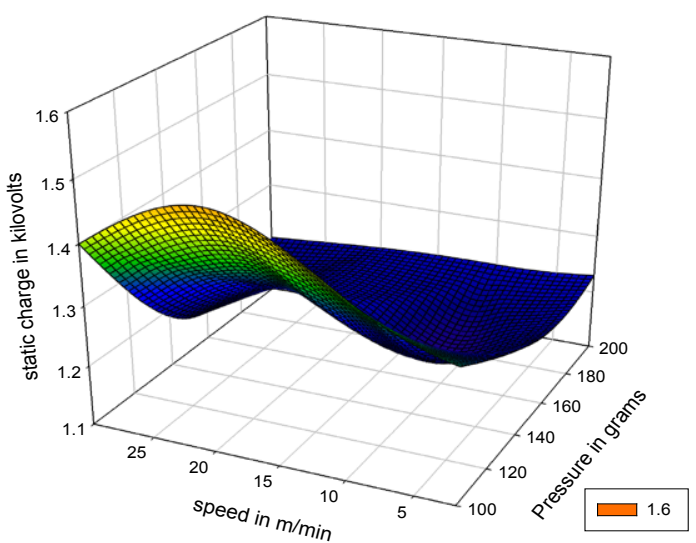

Figure 5: Effect of pressure and speed on electrostatic discharge properties of cotton fabrics.

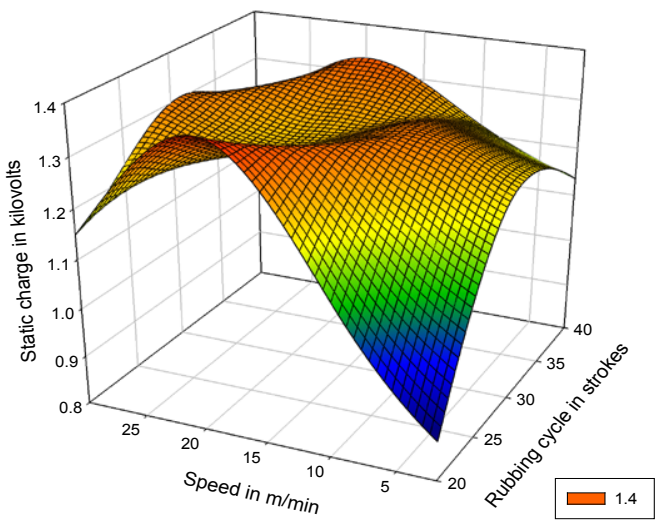

Figure 6: Effect of rubbing cycle and speed on electrostatic discharge properties of cotton fabrics.

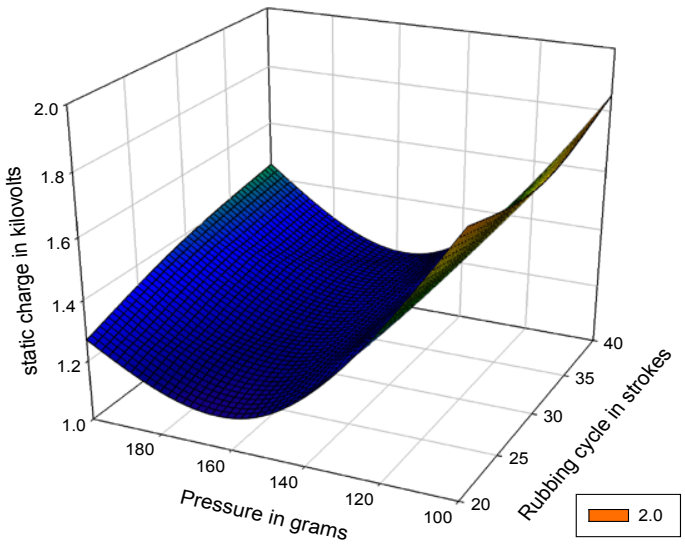

Figure 7: Effect of pressure and rubbing cycle on electrostatic discharge properties of PC blend fabrics.

was also observed that the cotton woven fabrics have less static in high humidity conditions because they observed water from the atmosphere and this water conduct and helps to dissipate and distribute the electrical static charge and also cotton fabrics are ineffective at dissipating static electric charge at very low level RH. It was understood that there was a significant effect between number of rubbing cycle and pressure and speed on electrostatic discharge properties of cotton woven fabrics. It was also found that higher number of rubbing cycle, pressure and speed had significant influences on the electrostatic discharge properties

\section{Electrostatic discharge properties of PC blend fabrics}

It was observed from the Figures 7-9, that the PC blend woven fabrics have static discharge value range from 1.12-1.85 kilovolts under various control factors of rubbing cycles, pressure and speed as per the Box Behnken experimental design. It was found that the PC blend fabrics have less electrostatic discharge generation value than the polyester woven fabric, but higher than the cotton woven fabrics. It was understood that there was a significant effect between number of rubbing cycle and pressure and speed on electrostatic discharge properties of PC blend woven fabrics. It was also found that higher number of rubbing cycle, pressure and speed had significant influences on the electrostatic discharge properties. 


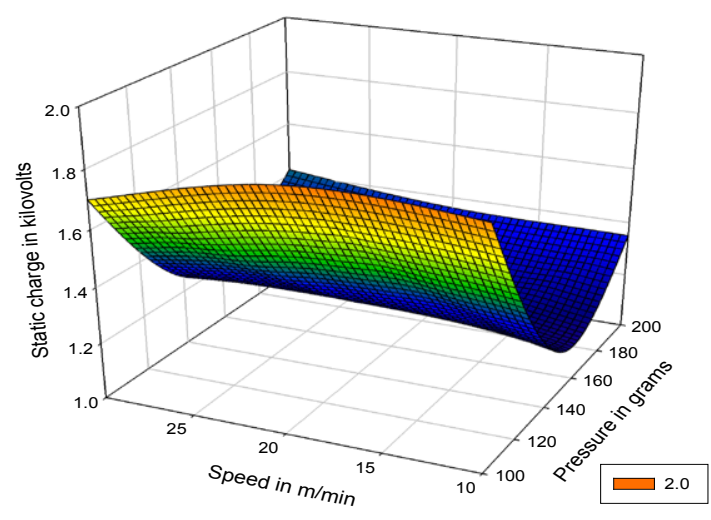

Figure 8: Effect of pressure and speed on electrostatic discharge properties of PC blend fabrics.

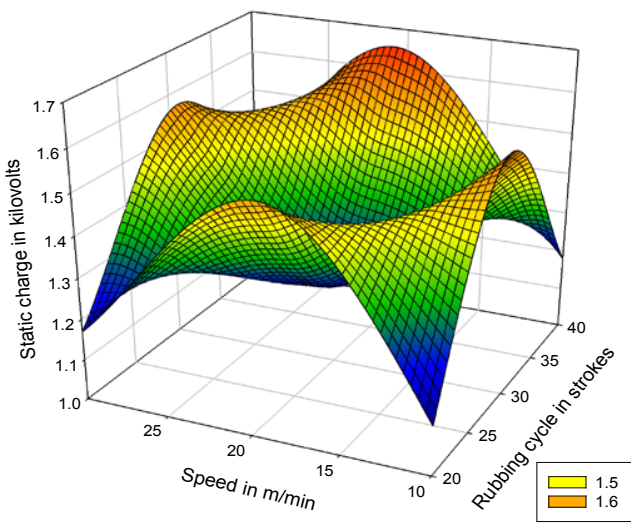

Figure 9: Effect of rubbing cycle and speed on electrostatic discharge properties of PC blend fabrics.

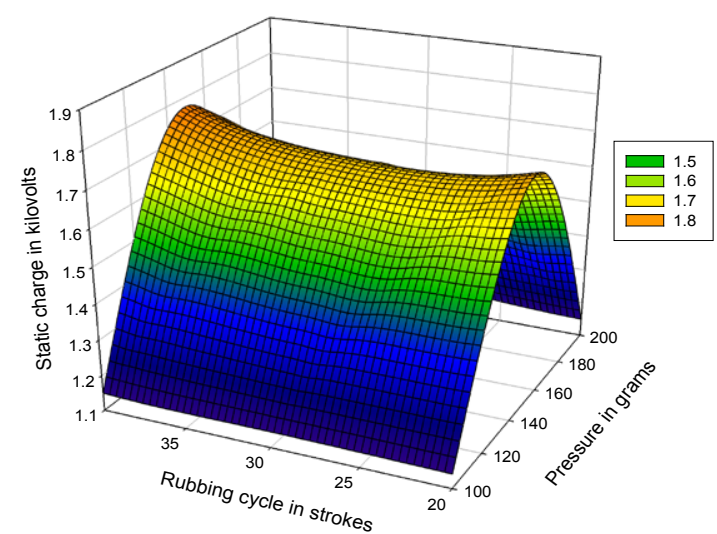

Figure 10: Effect of pressure and rubbing cycle on electrostatic discharge properties of Silk fabrics.

\section{The electrostatic discharge properties of silk woven fabrics}

It was observed from the Figures 10-12, that the silk woven fabric have electrostatic discharge generation value range from 1.1-1.82 kilovolts under the various controlled factors of number of rubbing cycles, speed and pressure as per the Box Behnken experimental design. The silk woven fabric less electrostatic discharge than polyester woven fabric, it is mainly due to the moisture regain value of silk woven fabric (11\%). Hence the silk woven fabrics have conduct and dissipate the electrostatic charge easily than the polyester woven fabric. It was understood that there was a significant effect between number of rubbing cycle and pressure and speed on electrostatic discharge properties of PC blend woven fabrics. It was also found that higher number of rubbing cycle, pressure and speed had significantly influence the electrostatic discharge properties.

\section{The electrostatic discharge properties of glass woven fabrics}

It was observed from Figures 13-15, that the glass woven fabric have very high electrostatic discharge value range from 1.5-2.88 kilovolts under various controlled factors of rubbing cycles, speed and pressure as per the Box Behnken experimental design. It was found that the glass woven fabric have more electrostatic discharge value than polyester, PC blend, silk and cotton woven fabrics. Since, the glass fibre woven fabric does not absorb the moisture and water; hence there is more accumulation of static electric charge over the surface of the glass woven fabrics than other woven fabric materials and also there is no any conducting or dissipating or distribution of static electric charge.

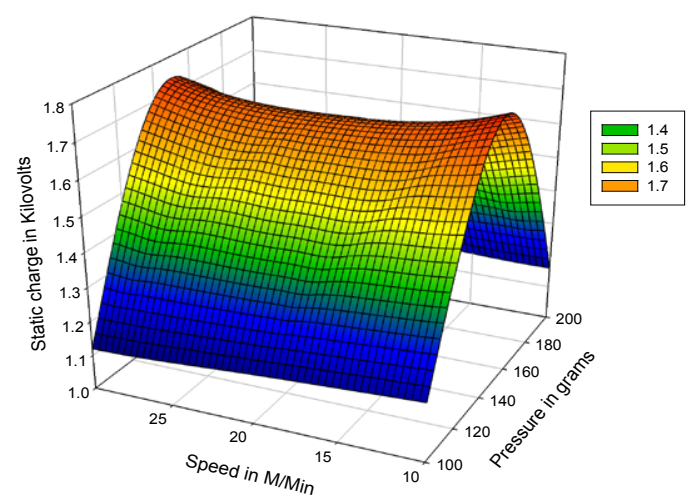

Figure 11: Effect of pressure and speed on electrostatic discharge properties of Silk fabrics.

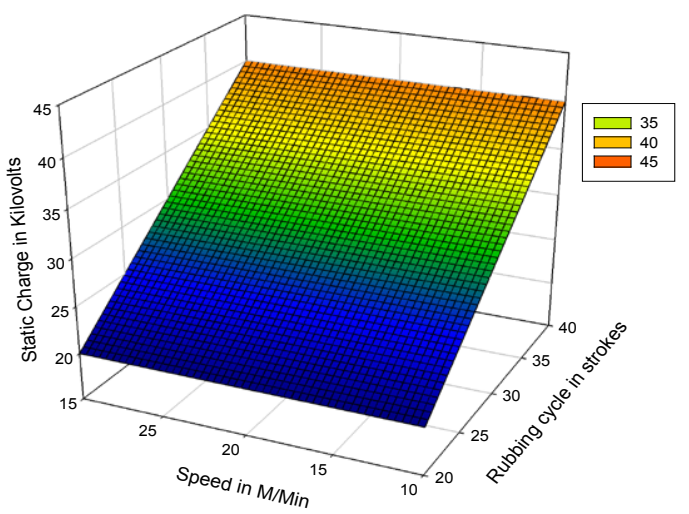

Figure 12: Effect of rubbing cycle and speed on electrostatic discharge properties of Silk fabrics. 
Citation: Perumalraj R (2016) Characterization of Electrostatic Discharge Properties of Woven Fabrics. J Textile Sci Eng 6: 235. doi:10.4172/21658064.1000235

Page 5 of 6

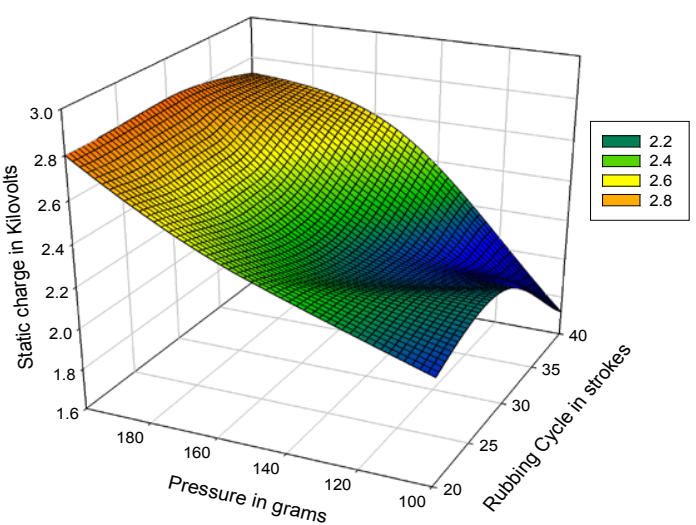

Figure 13: Effect of pressure and rubbing cycle on electrostatic discharge properties of Glass fabrics.

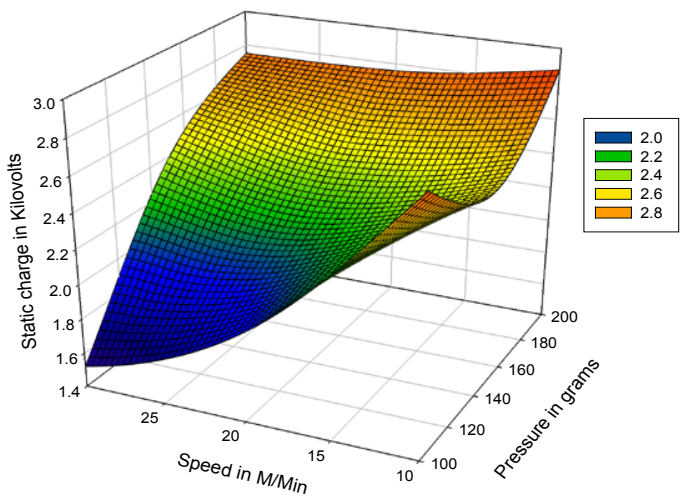

Figure 14: Effect of pressure and speed on Electrostatic discharge properties of Glass fabrics.

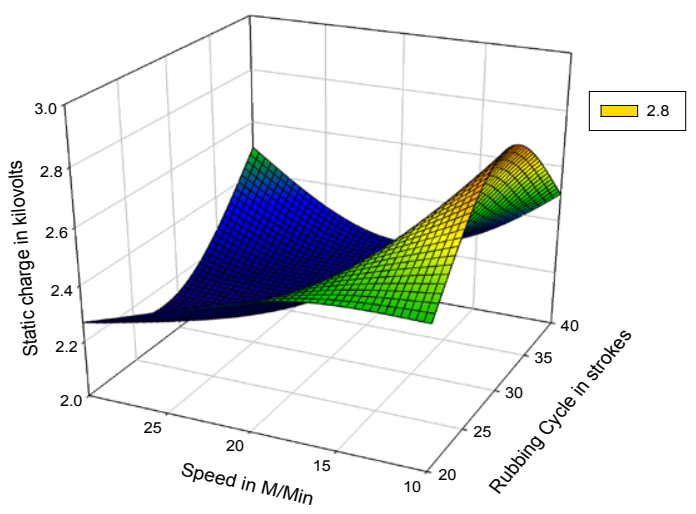

Figure 15: Effect of rubbing cycle and speed on Electrostatic discharge properties of Glass fabrics.

In general, the static electricity is the accumulation of electrical charges on the surface of the material, usually an insulator or non-conductor of electricity. It called "static" because there is no current flowing, as there is in alternative current (AC) or direct current (DC) electricity.

\begin{tabular}{|c|c|c|}
\hline SI. No. & Process parameter & Optimum level \\
\hline & Rubbing cycle & + \\
\hline & Pressure & 0 \\
\hline & Speed & + \\
\hline
\end{tabular}

Table 2: Optimum level process parameter of electrostatic discharge tester.

The glass and silk fibre woven fabrics have the greatest tendency to give up electrons and gain a positive electric charge, but in case of polyester woven fabric have the greatest tendency to attract electrons and gain a negative electrical charge.

The regression equations were formed using co-efficient obtained in the Box Behnken experimental design to assess the static electricity charge of the textile woven fabrics. Regression equation analysis for various woven fabrics is equated as $\mathrm{yl}=-198.310232 \mathrm{a}-$ $2.51277 \times 1+1.719121 \times 2+0.918667 \times 3$ where $y 1$ indicates the average of static charge generated, $\mathrm{x} 1, \mathrm{x} 2$ and $\mathrm{x} 3$ are the three factors and levels i.e. rubbing cycle, pressure and speed. The above equation is formed in this exercise and appeared to fit in a better way with the actual value obtained at all level, expressed by the higher correlation values.

The three optimum process parameters obtained from data and graphs were analyzed for best occurrence of each process parameter and once set of process parameter is obtained to find out the (i) optimum level of each variable,(ii) best trial. The process parameters for optimum results of electrostatic discharge are shown in the Table 2.

\section{Conclusion}

The electrostatic properties of various woven fabrics have mainly depends upon the control factors of number of rubbing cycle, pressure and speed of electrostatic discharge tester. The following conclusion can be drawn from this study.

- The glass woven fabric have more static charge generation than polyester, PC blend, silk and cotton woven materials.

- The polyester woven fabrics have more static electrostatic charge accumulation over the surface of the fabrics than the cotton, PC blend, silk and cotton.

- The glass and silk fibre woven fabrics have greatest tendency to give up electrons and gain a positive electrical charge.

- The polyester fibre woven fabric have greatest tendency to attract electrons and gain a negative electrical charge.

- The optimum process parameters were analyzed and it was found that rubbing cycle $(+)$, pressure $(0)$ and speed $(+)$ were obtained for effective measurement of electrostatic discharge properties of various types of woven fabrics.

\section{References}

1. Slade PE (1998) Antistats. Handbook of Fiber Finish Technology. New York, USA.

2. Bailey, Adrian G (2001) The Charging of Insulators. Journal of Electrostatics 51-52: 82-90.

3. Castle GSP (1997) Contact Charging between Insulators. Journal of Electrostatic 40-41: 3-12.

4. Arita Y, Shiratori SS, Ikezaki K (2003) Methods for the Detection and Visualization of Charge Trapping Sites in Amorphous Parts in Crystalline Polymers. Journal of Electrostatics 57: 263-271.

5. Taylor DM, Secker PE (1994) Industrial Electrostatics: Fundamentals and Measurements. John Wiley and Sons New York, USA 
Citation: Perumalraj R (2016) Characterization of Electrostatic Discharge Properties of Woven Fabrics. J Textile Sci Eng 6: 235. doi:10.4172/21658064.1000235

6. Gompf R (1988) Standard test method for evaluating triboelectric charge generation and decay. NASA Report.

7. Chubb JN (1990) Instrumentation and standards for testing static control materials. IEEE Trans Ind App 26: 1182-1187.

8. Buhler C, Calle C, Clements S, Ritz M, Starnes J (2006) Test methodology to evaluate the safety of materials using spark incendivity. Journal of Electrostatics 64: 744-751.

9. Chubb JN (1999) The assessment of materials by tribo and corona charging and charge decay measurement. Inst Physics ‘Electrostatics 163: 329-333.

10. Chubb JN (1996) Corona charging of practical materials for charge decay measurements. Journal of Electrostatic 37: 53-65.

11. (2000) IEC 61340-2-1 Measurement methods in electrostatics - Test method to measure the ability of materials and surfaces to dissipate static electric charge. International Electrotechnical Commission.

12. Chubb JN, Malinverni $P$ (1992) Comparative studies on methods of charge decay measurement. Journal of Electrostatics 30: 273-283.

13. Chubb JN (1995) Dependence of charge decay characteristics on charging Parameters. York, USA.
14. Jean C (1987) Electrostatics: Principles, problems and Applications. Adam Hilger.

15. Berezin AA (1995) Electrification of Solid Materials. Handbook of Electrostatic Processes, New York, USA.

16. Morton WE, Hearle JWS (1993) Physical Properties of Textile Fibers. Manchester UK.

17. Vosteen, William E (1984) A Review of Current Electrostatic Measuring Techniques and Their Limitations. Electrical Overstress Exposition.

18. Noll CG (1995) Electrostatic Charge Elimination Techniques. Handbook of Electrostatic Processes. New York, USA.

19. Kacprzyk R, Stec C (1997) Measurement of the Surface Charge Density on Moving Webs. Journal of Electronics 40-41: 455-461.

20. Seaver AE (1995) Analysis of Electrostatic Measurements on Non-Conducting Webs. Journal of Electrostatics 35: 231-243.

21. Durkin WJ (1995) Dangers in Interpreting Electrostatic Measurements on Plastic Webs. Journal of Electrostatics 35: 215-229. 